\title{
Hibernators, their awakeners and the roles of subsequent authoritative citers
}

\author{
Xiaojun $\mathrm{Hu}^{1}$, Xiaoyue $\mathrm{Hu}^{1}$, Yuning Zhang ${ }^{1}$, Ronald Rousseau ${ }^{2.3}$ \\ ${ }^{1}$ Medical Information Center, Zhejiang \\ University School of Medicine, Hangzhou 310058, CHINA \\ ${ }^{2} \mathrm{KU}$ Leuven, ECOOM, B-3000 Leuven BELGIUM \\ ${ }^{3}$ University of Antwerp (UA), Faculty of Social Sciences, \\ B-2020 Antwerp, BELGIUM \\ xjhu@zju.edu.cn (corresponding author); 21618446@zju.edu.cn, \\ yuningz@zju.edu.cn; ronald.rousseau@kuleuven.be (corresponding author)
}

\begin{abstract}
In this contribution we study four examples of hibernators and their citation relations with their awakeners. We, moreover, introduce the notion of authoritative citers, a group of articles that, like the awakener, cite the hibernator and play similar roles as the awakener. Yet, the interplay between the hibernator, the awakener and authoritative citers may differ considerably depending on the case at hand. The results of our study show that authoritative citers play an important role in spreading the knowledge of the hibernator and keeping it in the scientific limelight. This observation provides new insights in the role played by hibernators in scientific evolution.
\end{abstract}

Keywords: Hibernators; Sleeping Beauties; Awakeners; Authoritative citers; Delayed recognition; Citation evolution.

\section{INTRODUCTION}

The phenomenon of articles suffering from delayed recognition, renamed Sleeping Beauties by van Raan (2004), has recently attracted a lot of attention in the field of informetrics (Braun, Glänzel and Schubert 2010; Costas, van Leeuwen and van Raan 2010; Li and Ye 2012; Li 2014; Ke et al. 2015; Du and Wu 2016; Li and Shi 2016; Li and Ye 2016). In order to introduce a gender-neutral terminology we, however, replace the term "Sleeping Beauty" by "hibernator" and "Prince" by 'awakener".

As an inseparable partner in the story of the hibernator (HIB) also the awakener (AW) has led to investigations in informetrics. The relation between the AW and the HIB forms an interesting aspect in citation studies in general and of the characterization of HIBs in particular (van Raan 2004; Braun, Glänzel and Schubert 2010). Recently, HIBs and their AWs have been discussed in the context of technological innovation (Teixeira, Vieira and Abreu 2017; van Raan 2015; 2017). In van Raan (2015; 2017) the author explores HIBs cited in patents as scientific non-patent references and the relation with inventor-author links, showing among others that tunable co-citation analysis is a powerful tool to discover the $\mathrm{AW}(\mathrm{s})$ and other important application-oriented work directly related to the phenomenon of HIBs. The word 'tunable' in the previous sentence refers to the fact that the author wrote an algorithm in which parameters used to define the length of the hibernation, the depth of the hibernation, the hibernating period and intensity can be tuned within a certain range so 
that the term HIB refers to a continuum (a fact also put forward in Ke et al. 2015). The term tunable in conjunction with the term co-citation further refers to the fact that parameters for co-citation thresholds (concretely in VOSviewer) can also be tuned to the investigation at hand. As we neither have this algorithm nor the enhanced Web of Science (WoS) database of the author's institute (CWTS, Leiden University) we just require that the AW is the first to cite the HIB after a hibernating period and has a co-citation relation with the HIB (see further for details).

However, many investigations state that it is not always easy to decide which paper might be considered to be the AW (Walker 2008; Armbruster et al., 2008; Kozak 2013; Teixeira, Vieira and Abreu 2017). Often there are many authoritative citers (see further for a precise definition) and the first citation is not always the most influential. In this investigation we pay special attention to these authoritative citers and the results of their interactions with the HIB, taking co-citations, as in (van Raan 2017) and several citation generations into account (Hu, Rousseau and Chen 2011).

The objective of this study is to identify and highlight the role of authoritative citers in the evolution of HIBs, providing new insights in HIB-related research. Concretely, we try to answer the following research questions:

a) How is an authoritative citers of a hibernator identified?

b) What is the role played by authoritative citers?

\section{METHODOLOGY}

We present our methodology in six steps.

(i) Selection of examples of hibernators

We investigate four examples of HIBs: three published in the year 1980, reported in (Glänzel, Schlemmer, and Thijs 2003; Braun, Glänzel and Schubert 2010) and one published in 1986 and studied by van Raan (2004). These four articles are:

a) Edwards, J.H., and Feast, W.J. 1980, published in Polymer. Denoted in short as HIB1[Edwards];

b) Lis, T. 1980, published in Acta Crystallographica Section B - Structural Science. Denoted in short as HIB2-[Lis];

c) Romans, L.J. 1986, published in Physics Letters B. Denoted in short HIB3-[Romans];

d) Waite, D.A., Eyles, E.F., Tonkin, S.L., \& O'Donell, T.V. 1980, published in Clinical Allergy. Denoted in short as HIB4-[Waite]

\section{(ii) Identification of the AW}

According to van Raan's definition (van Raan 2004), an article is a HIB's AW if is the first citing article of the HIB after its deep hibernation period (at most 5 citations in 5 years, at most 10 citations in 10 years) or less deep hibernation (5-10 citations in 5 years, 10-20 citations in 10 years). In order to be considered a legitimate AW, this article must, moreover, have a substantial number of co-citations with the HIB (Braun, Glänzel and Schubert 2010; van Raan 2017). We note that in using the vague term 'substantial' we follow (Braun, Glänzel and Schubert, p. 196), who actually wrote 'considerable' and, imprecise as this may be, we follow these authors as it makes no sense to try to define a precise threshold. Exact numbers of cocitations will be shown when discussing AWs and authoritative citers. 


\section{(iii) Definition of authoritative citers}

The term authoritative citer (AC) refers to an article that has the same characteristics as the AW but just is not the first. These articles too play an important role in the later citation performance of a HIB (Walker 2008; Armbruster et al. 2008; Du and Wu 2016). Concretely, near the time when the HIB awakens, these articles are often, but not always, already highly cited papers themselves, and receive a substantial number of co-citations with the HIB.

\section{(iv) A thorough analysis of subsequent generations}

In order to investigate the story of the HIB, the AW and ACs we conduct a citation analysis of the scientific offspring of the AW and of the ACs, and make comparisons between the number of articles citing the HIB, the AW and the ACs. All data are extracted from the WoS and updated on July 10, 2017.

\section{(v) Obtaining the impact factors of journals in which HIB and AW are published}

Following a suggestion by Braun, Glänzel and Schubert (2010), for more details see the subsequent section, impact factors (in short IFs) are collected from the Journal Citation Reports (two years after publication).

\section{(vi) Obtaining the bibliographical details of HIBs, AWs and ACs.}

The full bibliographical data of the HIB, their AW and ACs are shown in the Appendix.

\section{FINDINGS AND DISCUSSIONS}

We found several types of ACs when studying the citation evolutions of HIBs. Before going into details we recall that Braun, Glänzel and Schubert $(2010$, p. 196) observed that

the average impact factor of the journals in which the Princes were published is more than twice as high as that of the Sleeping Beauties.

They added that

This is, of course, exactly the way in which the 'awakening' mechanism works. Papers published in a journal of lower visibility (IF) may be spotlighted by getting cited in a higher visibility journal.

For this reason, we too will pay attention to the impact factor of the journal in which citing articles were published. The impact factors shown are these two years after publication: for an article published in the year $Y$ we show the impact factor, obtained from the Journal Citation Reports, for the year $\mathrm{Y}+2$. This two-year gap accounts, at least to some extent, for the natural citation delay between publication and first citation.

Next we discuss one by one, the four cases mentioned above.

Type I: The HIB and the AW are reasonably well co-cited but later new ACs, citers of the HIB and being co-cited with it, come to the fore. These ACs are cited by articles which are themselves more highly cited than the HIB.

HIB1-[Edwards] is a representative of this type. This article, published in 1980, received a total of 295 citations and has been in deep sleep until 1983 (two citations in four years). As a HIB it was awakened in 1984 by AW1 and afterwards, attracted quite some citations. Although AW1 is weak (was published in a low impact journal and received only 89 citations), 
AW1 and HIB1 received quite some co-citations (44 co-citations, see Table 1). However, HIB1 also attracted $A C 1(1)$ in 1988, leading to 22 co-citations; and further $A C 1(2)$ and $A C 1(3)$ in 1994 and 1997. These three ACs were strong (were published in high impact factor journals and received more than 1,000 citations). The yearly citation distribution of HIB1-[Edwards], its AW, and ACs are shown in Figure 1. Compared with the 295 citations received by HIB1 we find 42 items citing $A C 1(1), 9$ items citing $A C 1(2)$ and 21 items citing $A C 1(3)$ all with at least 296 received citations. We draw the attention of the reader to the obvious fact that all these second generation items have a shorter citation window than the HIB, hence are expected to receive - on average - less citations than the HIB. In this example the HIB and the AW are published in journals with a low or average impact factor. ACs are all published in journals with a high impact factor.

Table 1: Citation Data related to Edwards (295 citations; IF $=1.23$ ) as HIB, its AW and ACs

\begin{tabular}{|c|c|c|c|c|c|}
\hline $\mathrm{AW}$ and $\mathrm{ACs}$ & $\begin{array}{c}\text { Publication } \\
\text { Year }\end{array}$ & $\begin{array}{l}\text { Impact } \\
\text { Factor }\end{array}$ & $\begin{array}{l}\text { Received } \\
\text { citations }\end{array}$ & $\begin{array}{c}\text { HIB-AW and } \\
\text { HIB-AC } \\
\text { Co-citations }\end{array}$ & $\begin{array}{l}\text { Number of items, with } \\
\text { more than } 295 \text { citations, } \\
\text { citing the AW (first row } \\
\text { below) or an AC (next } \\
\text { rows) }\end{array}$ \\
\hline AW1-[Leising] & 1984 & 0.91 & 89 & 44 & 0 \\
\hline AC1(1)-[Heeger] & 1988 & 17.79 & 2,611 & 22 & 42 \\
\hline AC1(2)-[Brédas] & 1994 & 17.11 & 1,063 & 2 & 9 \\
\hline AC1(3)-[Novak] & 1997 & 20.23 & 1,091 & 5 & 21 \\
\hline
\end{tabular}

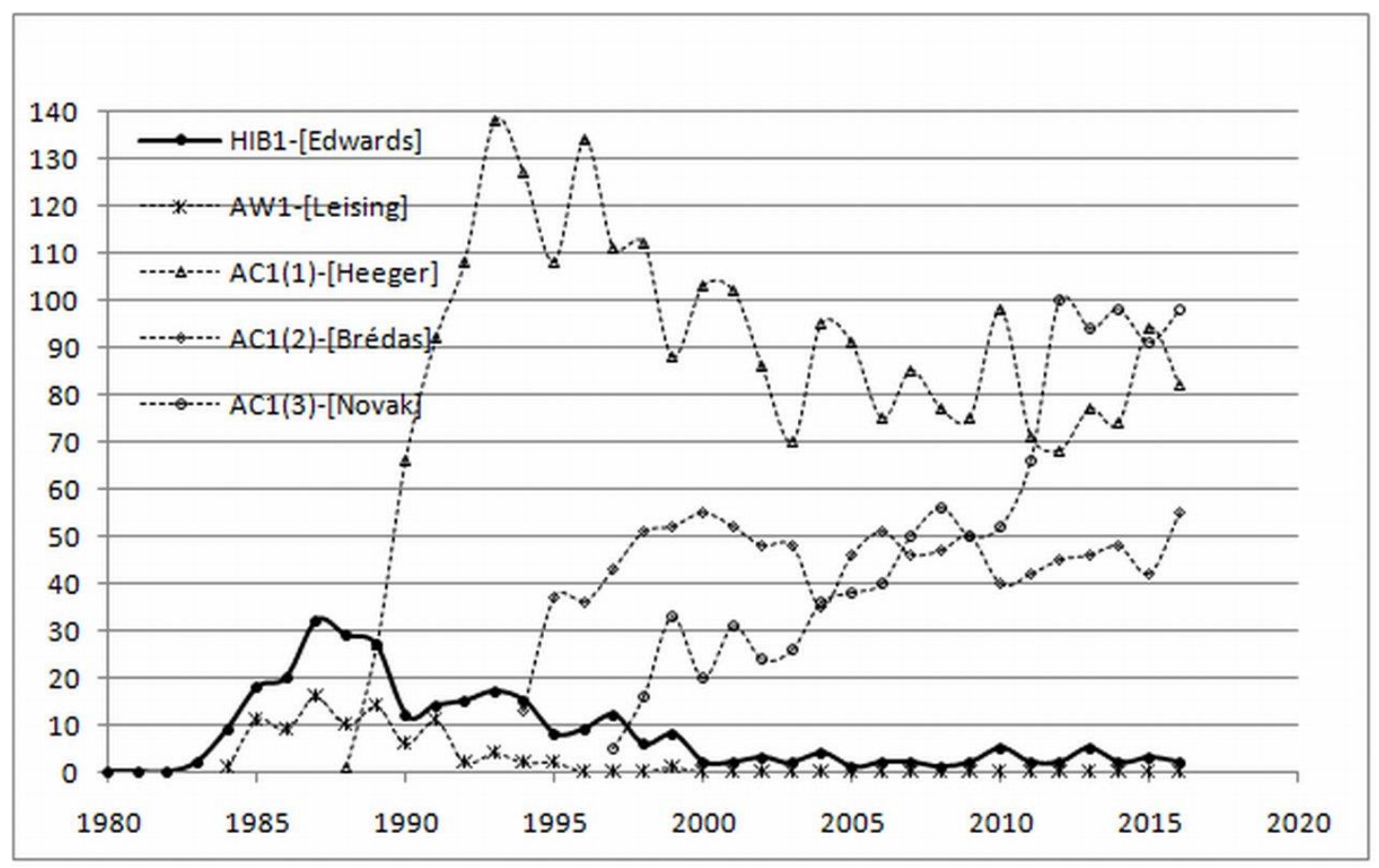

Figure 1: Yearly Citation Distribution of HIB1- [Edwards], their AW, and ACs 
Type II: The HIB does not have a lot of co-citations with the AW. Then later it meets a group of highly visible ACs with whom it received many co-citations.

Next we consider HIB2-[Lis], with a total of 782 citations in 2017, awakened by AW2, after a deep sleep of seven years (see Figure 2). However, it was further on awakened by several $A C s$, namely $A C 2(1), A C 2(2)$ and $A C 2(3)$. These articles all have a higher number of citations and give much more visibility to the HIB than the AW. Indeed, we found that the first LisSessoli pair, i.e. HIB2-[Lis] - AC2(1), was co-cited 436 times, the second Lis-Sessoli pair, i.e. HIB2-[Lis]-AC2(2), 369 times, and the Lis-Friedman pair, i.e. HIB2-[Lis]-AC2(3), 320 times (see Table 2). These co-citations are still going on resulting in respectively, 13, 9, and 7 co-citations this year (2017). Moreover, each AC has more highly cited citing articles than the AW (see the last column of Table 2). Obviously, compared to the AW, these three ACs have played a more important role in making the HIB better known and keep them in the scientific limelight. The AW was published in a journal with a much higher impact factor than the HIB. Yet, the ACs are published in journals with a still higher IF.

Table 2: Citation Data related to Lis (782 citations; IF $=1.16$ ) as HIB, their AW and ACs

\begin{tabular}{l||c||c||c||c||c}
\hline \hline AW and ACs & $\begin{array}{c}\text { Publication } \\
\text { Year }\end{array}$ & $\begin{array}{c}\text { Impact } \\
\text { Factor }\end{array}$ & $\begin{array}{c}\text { Received } \\
\text { citations }\end{array}$ & $\begin{array}{c}\text { HIB-AW or } \\
\text { HIB-AC } \\
\text { co-citations }\end{array}$ & $\begin{array}{l}\text { Number of items, with } \\
\text { more than 782 citations, } \\
\text { citing the AW (first row } \\
\text { below) or an AC(next } \\
\text { rows) }\end{array}$ \\
\hline \hline AW2-[Bashkin] & 1987 & 4.50 & 110 & 19 & 1 \\
\hline \hline AC2(1)-[Sessoli] & $1993 a$ & 27.07 & 2480 & 436 & 12 \\
\hline AC2(2)-[Sessoli] & $1993 \mathrm{~b}$ & 5.26 & 1611 & 369 & 6 \\
\hline \hline AC2(3)-[Friedman] & 1996 & 6.02 & 1486 & 320 & 9 \\
\hline \hline
\end{tabular}

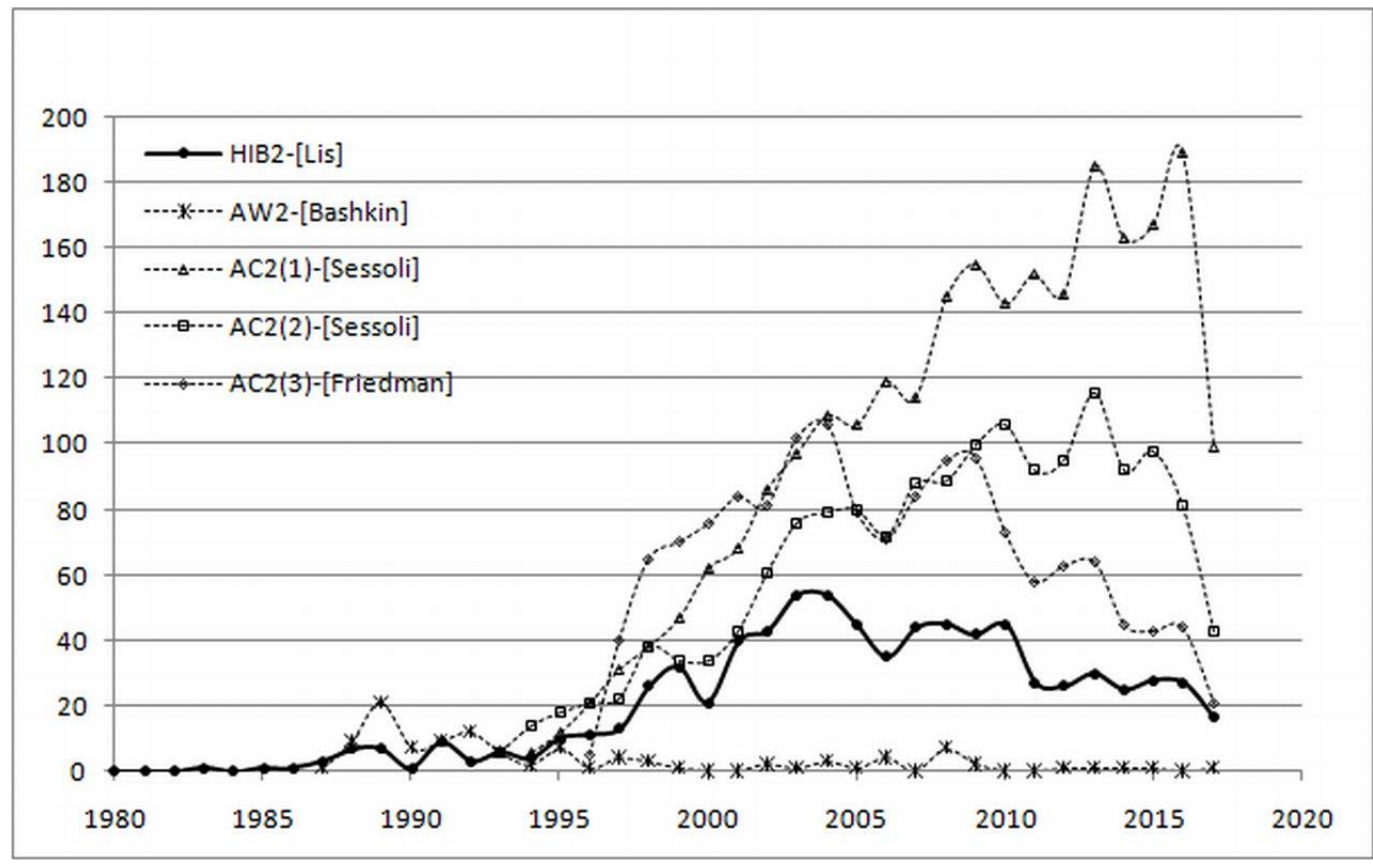

Figure 2: Yearly Citation Distribution of HIB2- [Lis], its AW, and ACs 
Type III: The AW is really the most important citer, yet the HIB still attracted a group of 'nice' ACs later. The AW and the ACs all have highly-cited offspring, but the AW has more.

After 10 years of deep sleep, as depicted in Figure 3, HIB3-[Romans] received the first citation in 1995 from its awakener, AW3, and became so influential that it received 80 citations during the period 1995-1999, reaching a total of 358 citations. AW3 received 1,670 citations and 85 co-citations with HIB3, and was really the first one to awaken Romans' article. Yet, a few years later, some other ACs became interested in Romans' article and made contributions related to HIB3 (see their co-citations in Table 3). Compared to the AW, the ACs played assisting roles in bringing and keeping the HIB to the scientific limelight. One can see that, in this example the AW and the ACs all have highly cited offspring: 29 items citing AW3, 10 items citing $A C 3(1), 7$ items citing $A C 3(2)$ and 10 items, citing $A C 3(3)$ received more than 358 citations (the number of citations received by HIB3-[Romans]). Although the ACs played a less significant role than the AW, they all contributed in subsequent citation generations to the scientific influence of the HIB. This example confirms the observation made in Braun, Glänzel and Schubert (2010) that the AW is published in a journal with an impact factor almost the double of that of the HIB's journal.

Table 3: Citation Data related to Romans (358 citations; IF $=3.61$ ) as HIB, its AW and ACs

\begin{tabular}{|c|c|c|c|c|c|}
\hline$A W$ and $A C s$ & $\begin{array}{c}\text { Publication } \\
\text { Year }\end{array}$ & $\begin{array}{l}\text { Impact } \\
\text { Factor }\end{array}$ & $\begin{array}{c}\text { Received } \\
\text { citations }\end{array}$ & $\begin{array}{c}\text { HIB-AW or } \\
\text { HIB-AC } \\
\text { co-citations }\end{array}$ & $\begin{array}{l}\text { Number of items, } \\
\text { with more than } 358 \\
\text { citations, citing the } \\
\text { AW (first row below) } \\
\text { or an AC(next rows) }\end{array}$ \\
\hline AW3-[Polchinski] & 1995 & 6.14 & 1679 & 85 & 29 \\
\hline AC3(1)-[Lukas] & 1999 & 4.36 & 464 & 11 & 10 \\
\hline AC3(2)-[Myers] & 1999 & 8.66 & 902 & 12 & 7 \\
\hline AC3(3)-[Maldacena] & 2001 & 0.91 & 551 & 13 & 10 \\
\hline
\end{tabular}

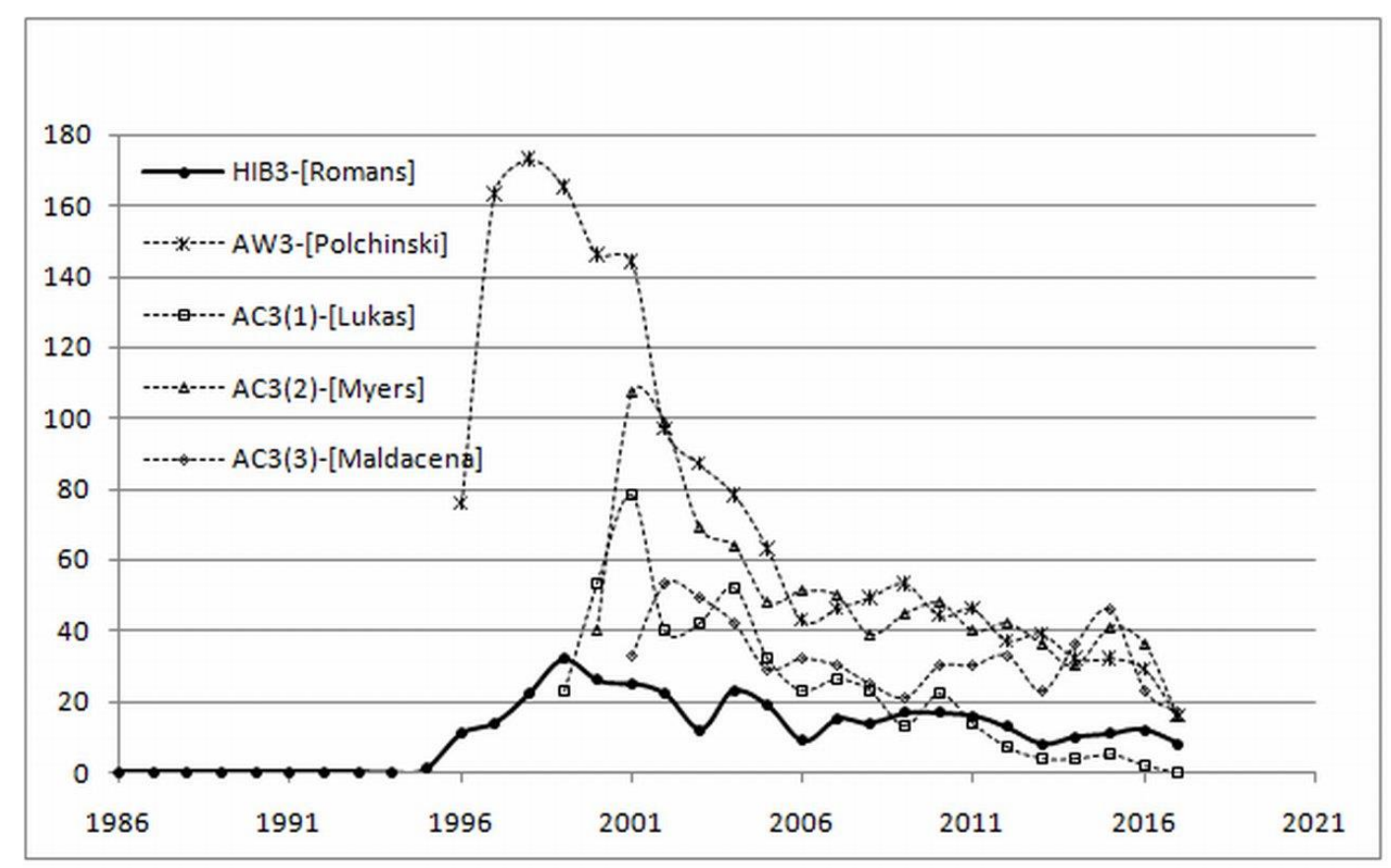

Figure 3: Yearly Citation Distribution of HIB3-[Romans], their AW and ACs 
Type IV: In terms of co-citations the AW and ACs contribute in a similar way to the visibility of the HIB. Yet, these ACs are more highly cited and so is their offspring.

Next we consider HIB4-[Waite] published in 1980. AW4 first cited HIB4-[Waite] in 1983 leading to its awakening. Yet, neither AW4 nor HIB4 became very active (in terms of received citations, see Figure 4 and Table 4). They also did not receive many co-citations: only 9 up to July 2017. Yet, after 6-12 years, HIB4 was frequently triggered by some ACs: AC4(1)-AC4(5). These 5 ACs all have a higher number of citations than AW4, and received a similar number or even more co-citations with HIB4 than the HIB4-AW4 couple. Again, we see that, each AC has much more highly-cited offspring than the AW (see Table 4). In this example the HIB, the $A W$ and most ACs - AC4(5) being the exception - are published in journals with a low or average impact factor.

Table 4: Citation data related to Waite (165 citations; IF $=1.32$ ) as HIB, their AW and ACs

\begin{tabular}{l||l||l||l||l||l}
\hline \hline AW and ACs & $\begin{array}{l}\text { Publication } \\
\text { Year }\end{array}$ & $\begin{array}{l}\text { Impact } \\
\text { Factor }\end{array}$ & $\begin{array}{l}\text { Received } \\
\text { citations }\end{array}$ & $\begin{array}{l}\text { HIB-AW } \\
\text { and HIB-AC } \\
\text { co-citations }\end{array}$ & $\begin{array}{l}\text { Number of items, with } \\
\text { more than 165 citations, } \\
\text { citing the AW (first row } \\
\text { below) or an AC(next } \\
\text { rows) }\end{array}$ \\
\hline \hline AW4-[Woolcock] & 1983 & 0.79 & 47 & 9 & 6 \\
\hline \hline AC4(1)-[Aberg] & 1989 & 1.91 & 292 & 15 & 29 \\
\hline \hline AC4(2)-[Seaton] & 1994 & 1.96 & 344 & 9 & 21 \\
\hline \hline AC4(3)-[Braback] & 1994 & 2.59 & 189 & 8 & 52 \\
\hline \hline AC4(4)-[Astheir] & 1995 & 1.92 & 1831 & 13 & 74 \\
\hline \hline AC4(5)-[Shirakawa] & 1997 & 24.60 & 982 & 14 & \\
\hline \hline
\end{tabular}

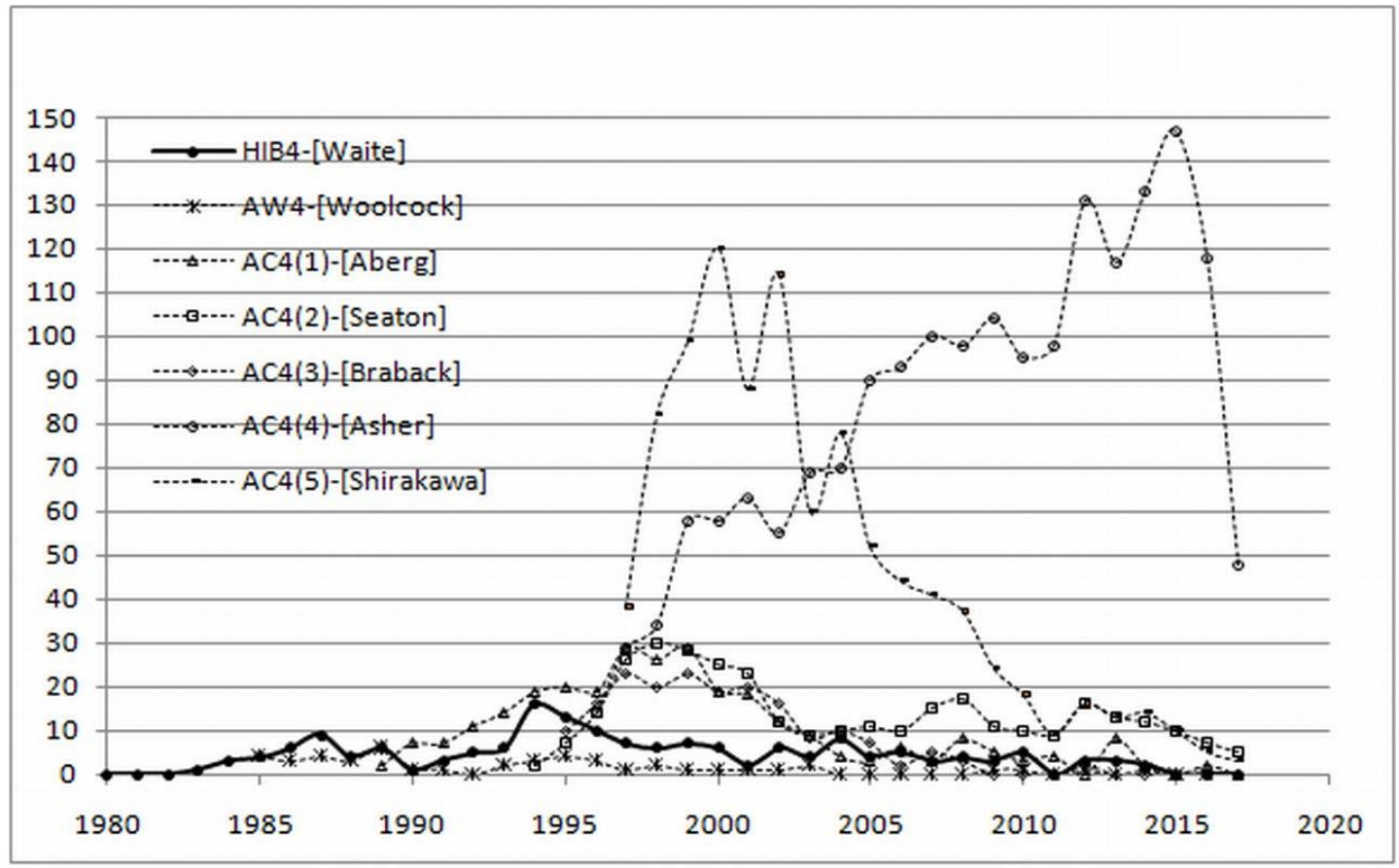

Figure 4: Yearly Citation Distribution of HIB4-[Waite], their AW, and ACs

One may observe an interesting phenomenon reflected in all our examples, namely the existence of a substantial number of highly cited items citing ACs. These second-generation items received a higher number of citations in a shorter time window than the HIB. Being an 
essential part of the continuing story of the HIB's citation evolution we referred to them as highly-cited offspring. Without any doubt, they play an important role to better understand HIBs and their citation evolution.

\section{CONCLUSIONS}

Our investigations provide new insight in the study of HIBs and their citation histories. We introduced the notion of $A C s$ and emphasized the role they played. Examples showed that the interplay between the HIB, AW and ACs may be of different types as summarized below:

a) Many ACs play important roles to make the HIB better known and keep it in the scientific limelight; hence ACs deserve more attention in HIB studies. Moreover, co-citation analysis of HIB-AC pairs help us gaining more insight in their citation history and evolution;

b) HIBs (zeroth generation) may be the source of highly-cited articles (second generation) citing ACs (first generation); this observation is a new aspect in the interaction of HIBs in scientific evolution.

c) Further citation generations play an essential role in the overall citation picture of scientific achievement, in particular in that of so-called hibernators.

d) The remark by Braun, Glänzel and Schubert (2010) that the AW is published in journals with a (much) higher impact factor than the HIB is not always confirmed. Among the ACs, however, it always happens that at least some are published in journals with a much higher impact factor than the HIB or the AW.

In conclusion we like to highlight that the study is confined to only four case types. Perhaps more types exist. Moreover, more research is needed to have an idea how frequently each of these types occur - some may occur frequently, while others may be rather rare.

\section{ACKNOWLEDGEMENT}

This work is supported by a grant of the National Natural Science Foundation of China (NSFC grant No. 71573225). We thank the reviewers for interesting suggestions, leading to a better article.

\section{REFERENCES}

Armbruster, H., Bikfalvi, A., Kinkel, S., and Lay, G. 2008. Organizational innovation: The challenge of measuring non-technical innovation in large-scale surveys. Technovation, Vol.28, no.10: 644-657. doi:10.1016/j.technovation.2008.03.003.

Braun, T., Glänzel, W., and Schubert, A. 2010. On Sleeping Beauties, Princes and other tales of citation distributions.... Research Evaluation, Vol.19, no.3: 195-202. doi: 10.3152/095820210X514210.

Costas, R., van Leeuwen, Th. N., and van Raan, A.F.J. 2010. Is scientific literature subject to a 'Sell-By-Date'? A general methodology to analyze the 'durability' of scientific documents. Journal of the American Society for Information Science and Technology, Vol.61, no.2: 329339. doi: 10.1002/asi.21244.

Du, J., and Wu, Y. 2016. A bibliometric framework for identifying "Princes" who wake up the "Sleeping Beauty" in challenge-type scientific discoveries. Journal of Data and 
Information Science, Vol.1, no.1: 50-68. doi: 10.20309/jdis.201605.

Glänzel, W., Schlemmer, B. and Thijs, B. 2003. Better late than never? On the chance to become highly cited only beyond the standard bibliometric time horizon. Scientometrics, Vol.58, no.3:571-586. doi: 10.1023/B:SCIE.0000006881.30700.ea

$\mathrm{Hu}, \mathrm{XJ}$., Rousseau, R., and Chen, J. 2011. On the definition of forward and backward citation generations. Journal of Informetrics, Vol.5, no.1: 27-36. doi: 10.1016/j.joi.2010.07.004 .

$\mathrm{Ke}, \mathrm{Q} ., \mathrm{Ferrara}, \mathrm{E}$. , Radicchi, F., and Flammini, A. 2015. Defining and identifying sleeping beauties in science. Proceedings of the National Academy of Sciences of the United States of America, Vol.112, no.24: 7426-7431. doi: 10.1073/pnas.1424329112

Kozak, M. 2013. Current science has its 'Sleeping Beauties'. Current Science, Vol.104, no.9: $1129-1130$.

Li, J. 2014. Citation curves of "all-elements-sleeping-beauties": "flash in the pan" first and then "delayed recognition". Scientometrics, Vol.100, no.2: 595-601. doi: https://doi.org/10.1007/s11192-013-1217-z.

Li, J., and Shi, DB. 2016. Sleeping beauties in genius work: When were they awakened? Journal of the Association for Information Science and Technology, Vol.67, no.2: 432-440. doi: 10.1002/asi.23380.

$\mathrm{Li}, \mathrm{J}$. and Ye, F.Y. 2012. The phenomenon of all-elements-sleeping-beauties in scientific literature. Scientometrics, Vol.92, no.3: 795-799. doi:10.1007/s11192-012-0643-7.

Li, J. and Ye, F.Y. 2016. Distinguishing sleeping beauties in science. Scientometrics, Vol.108, no. 2: 821-828.doi:10.1007/s11192-016-1977-3.

Teixeira, A.A.C., Vieira, P.C. and Abreu, A.P. 2017. Sleeping Beauties and their Princes in innovation studies. Scientometrics, Vol. 110, no.2: 541-580. doi:10.1007/s11192-0162186-9.

van Raan, A.F.J. 2004. Sleeping Beauties in science. Scientometrics, Vol.59, no.3: 467-472. doi: 10.1023/B:SCIE.0000018543.82441.f1.

van Raan, A.F.J. 2015. Dormitory of physical and engineering sciences: Sleeping Beauties may be sleeping innovations. PLoS One, Vol. 10, no. 10: e0139786. doi:10.1371/journal.pone.0139786.

van Raan, A.F.J. 2017.Sleeping beauties cited in patents: Is there also a dormitory of inventions? Scientometrics, Vol. 110, no. 3: 1123-1156. doi:10.1007/s11192-016-2215-8.

Walker, R. M. 2008. An empirical evaluation of innovation types and organizational and environmental characteristics: Towards a configuration framework. Journal of Public Administration Research and Theory, Vol. 18, no. 4: 591-615. doi:10.1093/jopart/mum026. 


\section{APPENDIX}

\section{List of Hibernators (HIB), Awakeners (AW) and Authoritative Citers (AC)}

\section{HIB1-[Edwards]}

HIB1. Edwards, J.H., and Feast, W.J. 1980. A new synthesis of poly(acetylene). Polymer, Vol. 21, no. 6: 595-596. doi: 10.1016/0032-3861(80)90311-0.

AW1. Leising, G. (1984). Fully oriented non-fibrous crystalline polyacetylene. Polymer Bulletin, 11(5), 401-405. [89 citations].

AC1(1). Heeger, A.J., Kivelson, S., Schrieffer, J.R. \& Su, W.-P. (1988).Solitons in conducting polymers. Reviews of Modern Physics, 60(3), 781-850[2611 citations].

AC1(2). Brédas, J.L., Adant, C., Tackx, P., Persoons, A. \& Pierce, B.M. (1994). Third-order nonlinear optical response in organic materials: Theoretical and experimental aspects. Chemical Reviews, 94(1), 243-278 [1063 citations].

AC1(3). Novák, P., Müller, K., Santhanam, K.S.V. \& Haas, O. (1997). Electrochemically active polymers for rechargeable batteries. Chemical Reviews, 97(1), 207-281 [1091 citations].

\section{HIB2-[Lis]}

HIB2. Lis, T. 1980. Preparation, structure and magnetic properties of a dodecanuclear mixedvalence manganese carboxylate. Acta Crystallographica Section B - Structural Science, Vol. 36, no.9: 2042-2046. doi: 10.1107/S0567740880007893.

AW2. Bashkin, J.S., Chang, H.R., Streib, W.E., Huffman, J.C., Hendrickson, D.N. \&Christou, G. (1987). Modelling the photosynthetic water oxidation center: Preparation and physical properties of a tetranuclear oxide bridged $\mathrm{Mn}$ complex corresponding to the native $\mathrm{S}_{2}$ state. Journal of the American Chemical Society, 109(21), 6502-6504 [110 citations].

AC2(1). Sessoli, R., Gatteschi, D., Caneschi, A. \& Novak, M.A. (1993a). Magnetic bistability in a metal-ion cluster. Nature, 365(6442), 141-143 [2480 citations].

AC2(2). Sessoli, R., Tsai, H.L., Schake, A.R., Wang, SY., Vincent, J.B., Folting, K., Gatteschi, D., Christou, G. \& Hendrickson, D.N. (1993b). High-spin molecules: $\left[\mathrm{MN}_{12} \mathrm{O}_{12}\left(\mathrm{O}_{2} \mathrm{CR}\right)_{16}\left(\mathrm{H}_{2} \mathrm{O}\right)_{4}\right]$. Journal of the American Chemical Society, 115(5), 1804-1816 [1611 citations].

AC2(3). Friedman, J.R., Sarachik, M.P., Tejada, J. \& Ziolo, R. (1996). Macroscopic measurement of resonant magnetization tunneling in high-spin molecules. Physical Review Letters, 76(20), 3830-3833 [1486 citations].

\section{HIB3-[Romans]}

HIB3. Romans, L.J. 1986. Massive $\mathrm{N}=2$ a supergravity in ten dimensions. Physics Letters $B$, Vol. 169, no. 4: 374-380. doi: 10.1016/0370-2693(86)90375-8.

AW3. Polchinski, J. (1995) Dirichlet branes and Ramond-Ramond charges. Physical Review Letters, 75(26), 4724-4727 [1679 citations].

AC3(1). Lukas, A., Ovrut, B.A., Stelle, K.S. \& Waldram, D. (1999). Universe as a domain wall. Physical review D, 59(8), 086001 [464 citations].

AC3(2). Myers, R.C. (1999). Dielectric-branes. Journal of High Energy Physics, 12, 022 [902 citations].

AC3(3). Maldacena, J. \& Nuñez, C. (2001). Supergravity description of field theories on curved manifolds and a no go theorem. International Journal of Modern Physics A, 16(5), 822-855 [551 citations].

\section{HIB4- [Waite]}

HIB4. Waite, D.A., Eyles, E.F., Tonkin, S.L., and O'Donell, T.V. 1980. Asthma prevalence in Tokelauan children in two environments. Clinical Allergy, Vol. 10, no. 1: 71-75. doi: 10.1111/j.1365-2222.1980.tb02082.x. 
AW4. Woolcock, A.J., Dowse, G.K., Temple, K., Stanley, H., Alpers, M.P. \& Turner, K.J. (1983). The prevalence of asthma in the South-Fore people of Papua New Guinea. A method for field studies of bronchial reactivity. European Journal of Respiratory Diseases, 64(8), 571-581[47 citations].

AC4(1). Aberg, N. (1989). Asthma and allergic rhinitis in Swedish conscripts. Clinical and Experimental Allergy, 19(1), 59-63 [292 citations].

AC4(2). Seaton, A., Godden, D.J. \& Brown, K. (1994). Increase in asthma: A more toxic environment or a more susceptible population. Thorax, 49(2), 171-174 [344 citations].

AC4(3). Braback, L., Breborowicz, A., Dreborg, S., Knutsson, A., Pieklik, H. \& Bjorksten, B. (1994). Atopic sensitization and respiratory symptoms among Polish and Swedish school children. Clinical and Experimental Allergy, 24(9), 826-835 [189 citations].

AC4(4). Astheir, M.l., et al. (1995). International study of asthma and allergies in childhood (ISAAC): Rationale and methods. European Respiratory Journal, 8(3), 483-491 [1831 citations].

AC4(5). Shirakawa, T., Enomoto, T., Shimazu, S. \& Hopkin, J.M. (1997).The inverse association between tuberculin responses and atopic disorder. Science, 275(5296), 77-79 [982 citations]. 